\title{
Entre Fios e Desafios: Indústria da Moda, Linguagem e Trabalho Escravo na Sociedade Imperialista
}

\author{
Entre Hilos y Desafios: Industria de la Moda, Lenguaje y Trabajo Esclavo \\ en la Sociedad Imperialista
}

\author{
Between Threads and Challenges: Fashion Industry, Language and Slave \\ Labor in the Imperialist Society
}

\author{
Sheila Daniela Medeiros dos Santos ${ }^{1}$
}

\begin{abstract}
Resumo
Este trabalho objetiva analisar a significação do conceito de slow fashion, presente nos interstícios da linguagem da moda e disseminado nas mídias sociais, no intuito de desvendar os pressupostos ideológicos contidos no uso deste termo como forma de combater o trabalho escravo na sociedade Imperialista. Para concretizar este estudo realizou-se uma pesquisa ancorada no referencial teórico de Vigotski $(2007,2009)$ e de Ortiz $(2009,2011)$. As análises dos dados revelam que não basta refletir sobre a descartabilidade da moda e aderir ao slow fashion como principal linha de ação para lutar contra o trabalho escravo nas cadeias produtivas da indústria da moda. A questão que prioritariamente se coloca é como perscrutar e enfrentar as imposições de um sistema econômico que se reestrutura de modo contínuo, no intuito de reinar soberano, reengendrando novas formas de organização de trabalho extremamente injustas, desiguais e desumanas.
\end{abstract}

Palavras-chave: Indústria da moda; linguagem; trabalho escravo.

\section{Resumen}

Este trabajo tiene como objetivo analizar el significad del concepto slow fashion, presente en los intersticios del lenguaje de la moda y difundido en los medios sociales con la intención de desvelar los supuestos ideológicos contenidos en el uso de este concepto como una manera de combatir el trabajo esclavo en la sociedad Imperialista. Para lograr este estudio se llevó a cabo una investigación basada en el marco teórico de Vigotski $(2007,2009)$ y Ortiz (2009, 2011). El análisis de los datos muestra que no es suficiente reflexionar sobre la moda desechable y adherir al slow fashion como la línea principal de acción para luchar contra el trabajo esclavo en la cadena de producción de la industria de la moda. La cuestión que surge en primer lugar es cómo investigar a fondo y enfrentar a la imposición de un sistema económico que se reestructura de forma continua con el fin de reinar soberano, reengendrando nuevas formas de organización del trabajo extremadamente injusto, desigual e inhumano.

Palabras claves: Industria de la moda; lenguaje; trabajo esclavo.

\begin{abstract}
This article aims to analyze the meaning of the concept of slow fashion presents in the interstices of the fashion language and disseminated in the social media, in order to unravel the ideological presupposed contained in the use of this term as a way to combat the slave labor in he Imperialist society. To carry out this study, the research anchored in the theoretical-methodological approach of Vigotski $(2007,2009)$ and Ortiz $(2009,2011)$. The analysis of the data reveals that it is not enough to reflect about the disposability of fashion and accept the slow fashion as the main line of action to combat the slave labor in the chains productive of the fashion industry. The prority question is to examine and confront the impositions of an economic system which restructures itself in a continuous way to reign sovereign, reconstruct new forms of work organization extremely unjust, unequal and inhuman.
\end{abstract}

Keywords: Fashion industry; language; slave labor.

\footnotetext{
${ }^{1}$ Doutora em Educação - UNICAMP; Docente na Faculdade de Educação - UFG; Goiânia, Goiás, Brasil;
} sheiladmsantos@gmail.com. Auxílio: FAPEG. 


\section{Introdução}

O último relatório publicado pela Organização Internacional do Trabalho (OIT), em 2014, revelou a existência de cerca de 21 milhões de pessoas vítimas de trabalho forçado em todo o mundo, assim como a estimativa de ganhos de 150 bilhões de dólares, a cada ano, à economia privada oriundos deste tipo de trabalho (OIT, 2014).

De acordo com o Decreto que ratificou a Convenção n. 29 da OIT de 1930 (OIT, 1957), o trabalho forçado inclui formas análogas à escravidão, as quais se caracterizam pelo trabalho degradante aliado ao cerceamento da liberdade, seja através da apreensão de documentos em razão de dívidas ilegalmente impostas ou das características geográficas do local, seja através do confinamento e da presença de guardas armados.

No mundo globalizado, práticas de trabalho ilegais são encontradas em larga escala na cadeia produtiva da moda e podem estar presentes na colheita do algodão, na fiação da fibra em fios, na costura da roupa e no processo final de produção.

Ocorre que, no final século XX, estas formas de trabalho análogas ao trabalho escravo se intensificaram ainda mais a partir do surgimento de um modelo de comercialização da moda denominado fast fashion, o qual se consolidou de forma arrebatadora.

O termo fast fashion foi forjado pelas grandes corporações do mundo da moda para fazer referência à produção rápida, compacta e contínua de novas coleções de roupas em um curto período de tempo, envolvendo alta circulação de mercadorias nas prateleiras.

Nesta direção, com o intuito de questionar o impacto da indústria do fast fashion sobre as pessoas e o mundo atual, principalmente sobre os países pobres que estavam oferecendo mão de obra para as grandes grifes internacionais, surgiu um movimento contrário ao fast fashion intitulado slow fashion, o qual significa, de acordo com seus idealizadores, uma nova forma de consumir moda que unifica princípios éticos, conscientes e de sustentabilidade no enfrentamento ao trabalho escravo (FLETCHER, 2007).

Ao considerar estes aspectos, o presente trabalho apresenta como objetivo analisar a significação do conceito de slow fashion, presente nos interstícios da linguagem da moda e disseminado nas mídias sociais, no intuito de desvendar os pressupostos ideológicos contidos no uso deste termo em uma sociedade consubstanciada pelo Imperialismo.

Para concretizar este estudo realizou-se uma pesquisa do tipo qualitativa, bibliográfica e documental, fundamentada no referencial teórico de Vigotski (2007, 2009) e de Ortiz (2009, 2011), em que optou-se pelo recorte analítico de materiais disponíveis sobre fast fashion e slow 
fashion em mídias sociais como blogs (publicações editoriais independentes) e sites de compartilhamento (Youtube).

Convém mencionar que, apesar de ter-se delimitado o processo de investigação em blogs e sites de compartilhamento, compreende-se mídias sociais como um termo amplo que refere-se à aplicações de internet fundamentadas nos conceitos da Web 2.0 (KAPLAN \& HAENLEIN, 2010), o qual inclui não apenas as duas ferramentas tecnológicas citadas, mas também as redes sociais (como o Facebook), os microblogs (como o Twitter) e as wikis (páginas de conteúdos de edição coletiva e livre).

O trabalho está organizado de tal forma que, primeiramente, procura explicitar os contornos conceituais do termo fast fashion, enfatizando as relações entre este sistema de produção adotado pela indústria da moda e o trabalho escravo na sociedade atual. Na sequência, dedica-se a circunscrever brevemente a significação do termo slow fashion, desvendando os pressupostos ideológicos contidos nesse novo movimento de consumir moda. E, por último, apresenta algumas considerações finais no sentido do mundo atual se contrapor a um sistema de produção que esgarça toda e qualquer tentativa de luta na construção de uma sociedade mais justa, igualitária e democrática.

\section{Fast fashion e trabalho escravo contemporâneo: breves considerações}

O termo fast fashion emerge, a partir do anos de 1980, como um conceito enleado pelo discurso da democratização da moda. Trata-se de um sistema de comercialização de roupas forjado na Europa que disseminou-se em escala mundial, cujo objetivo é prover o mercado com as novas tendências do mundo da moda de forma extremamente rápida, potencializando a competitividade e a rotatividade na cadeia de produção deste segmento (CAETANO, 2013).

Cietta (2010) explica que o sistema fast fashion consegue lançar uma coleção e colocála no mercado em poucas semanas, enquanto que o sistema tradicional de comercialização da moda, ao considerar desde a escolha de tendências e de matéria-prima para a produção até a disponibilização das roupas nas lojas para a venda, necessita de um prazo de aproximadamente 24 meses.

Outra diferença significativa entre um sistema e outro refere-se ao fato de que no fast fashion o consumidor é envolvido desde a definição do design do produto até o processo final de sua fabricação, de tal forma que apenas será produzido aquilo que o consumidor deseja e pretende realmente comprar. Já no sistema tradicional da moda, o consumidor escolhe as peças dentro de uma coleção já produzida e apresentada pelas grandes marcas, o que implica em ter 
disponíveis no mercado produtos que emplacam e/ou produtos que ficam encalhados nas prateleiras das lojas.

Deste modo, o fast fashion trabalha com profissionais que perseguem tendências (CIETTA, 2010) e priorizam a obtenção de informações junto aos consumidores, e não às lojas.

De acordo com Cietta (2010), o fast fashion não representa um modelo de produção para segmentos de baixo escalão que visa tão somente a cópia das distintas coleções de roupas lançadas pelos designers de grandes nomes, mas trata-se de uma estratégia e de um modelo organizativo que explora a natureza híbrida de produtos da moda.

Apesar de Cietta (2010) defender de modo incisivo este novo modelo de negócio, denominado fast fashion, é possível notar que se em décadas atrás os designers da moda mudavam toda uma sociedade ao criarem peças de roupas que demandavam novas silhuetas e novas posturas, na atualidade os designers se restringem a reciclar tendências do passado, uma vez que são pressionados a lançarem inúmeras coleções anualmente com vistas a uma única perspectiva: atingir os mais altos faturamentos.

Além disso, com o processo de globalização, o fast fashion marcou a entrada de grandes empresas da moda mundiais em países estrangeiros, afetando a produção local.

Cumpre lembrar que, embora o termo globalização, disseminado no final do século XX, fizesse referência a uma ideia (equivocada) de homogeneização social, econômica, cultural e territorial que culminava na dissolução das identidades locais e na consolidação de uma lógica única marcada por um espaço global despersonalizado, emergiu, concomitantemente neste momento histórico, uma vertente teórica contrária (IANNI, 2008; ORTIZ, 2011; SANTOS, 2003), no intuito de forjar o termo globalização em outra perspectiva, qual seja, a de um processo simultâneo e inextricavelmente uno e diverso, capaz de envolver noções distintas, como o global e o local/nacional, o homogêneo e o heterogêneo, de modo relacional (MARZOCHI, 2007).

A globalização pode ser caracterizada como um processo social que define uma nova situação. Ele vem marcado por um conjunto de condições e contradições. Um processo não é nunca homogêneo, tampouco harmonioso, isento de conflitos, nele se inserem interesses e instituições (ORTIZ, 2009, p. 248).

Marx e Engels (2010), no Manifesto comunista, já asseveravam o caráter globalizante do capitalismo. Nesta direção, em seu processo de (re)produção, o capital avulta-se tanto em profundidade como em extensão, não apenas reordenando modos de vida e territórios organizados e consolidados, como também incorporando novos espaços através de movimentos 
dialeticamente entrelaçados, os quais conduzem tendencialmente à produção de uma sociedade global.

Segundo Ianni (1994, 147), na sociedade global, "as relações, os processos e as estruturas econômicas, políticas, demográficas, geográficas, históricas, culturais e sociais, que se desenvolvem em escala mundial" tornam-se preeminentes às configurações e movimentações que se desenvolvem em esfera nacional.

Deste modo, na acepção de Ortiz (MELLO, BATISTA \& GUSMÃO, 2015) não há um mercado global homogêneo, nivelado pelas imposições mercadológicas, há uma distinção, o que não significa uma separação, entre o universo material da técnica e do mercado e o universo da cultura.

\begin{abstract}
A globalização é produzida e reproduzida segundo linhas de força. Conhecê- las é desvendar os seus traços hegemônicos. A ideia de situação é também fecunda para apreendê-la. Esta perspectiva analítica encerra algumas vantagens conceituais. Ela permite, em primeiro lugar, evitar uma oposição rígida entre o velho e o novo. $\mathrm{O}$ crucial não é a ruptura separando o passado do presente, mas o fato de ambos serem tensionados pelo fluxo que os atravessa. A contemporaneidade não se refere apenas ao novo, toda uma tradição a alimenta, a contrasta, e se faz atual. O tema é antigo, mas se redefine dentro do novo contexto, pois o potencial que ela conhecia, no momento da emergência do Estado-nação, se transforma (ORTIZ, 2009, p. 248).
\end{abstract}

Assim, na perspectiva analítica de Ortiz (2011), não existe uma cultura global, existe um processo de mundialização da cultura que, na sua amplitude planetária e na sua diversidade, articula-se ao movimento de globalização da técnica e da economia.

Evidentemente, a globalização não ocorre de modo linear, sem embates e resistências; ela atravessa períodos de crises e de aceleração, de avanços tecnológicos e de refreamento social e político. No entanto, atualmente, nota-se que a globalização encontra-se cada vez mais subordinada aos imperativos do capital financeiro e dos fluxos de mercantilização das corporações transnacionais.

Nesse ínterim, a globalização permite que as empresas das grandes grifes da moda mudem a produção das peças de roupas para países marcados pela pobreza e pela oferta de mãode-obra barata, de tal forma que sejam beneficiadas não apenas pela condição de miséria da população, mas também pelos privilégios econômicos concedidos pelos governos destes países, através da isenção de impostos, da manutenção de empresas prestadoras de serviços e da baixa fiscalização.

Por conseguinte, as forças econômicas e sociais do mundo globalizado possibilitam a intensificação alarmante das práticas de trabalho análogas à escravidão (OIT, 1957), uma vez que estas emergem quando os indivíduos não têm a possibilidade de suprir as suas necessidades 
básicas, ou seja, quando lhes é negado habitação, alimentação, saúde, educação, proteção e justiça social.

Nesta ambiência, a maior parte do trabalho realizado para fabricar uma coleção de roupas é repassado para diversas terceirizadas, e até quarteirizadas, de tal modo que o rastreamento de toda a trajetória percorrida no processo de fabricação das peças de vestuário, desde a matéria-prima até o produto final, torne-se difícil, permitindo que as atividades de exploração ilegais passem despercebidas (BARROS, 2016).

Portanto, a tendência do mercado denominado fast fashion gera uma série de polêmicas, pois se por um lado promove o aumento do faturamento para as grandes marcas da moda, por outro estimula o consumo exacerbado e o trabalho escravo em diversos países como: Camboja, Bangladesh, Índia, entre outros países da Ásia, África e América Latina.

Uma vez delineado estes aspectos, é possível afirmar que as chaves interpretativas trazidas por Ortiz (2006), a respeito da globalização e da mundialização da cultura, podem contribuir para o entendimento dos modos pelos quais as desigualdades sociais se inserem no contexto global.

De acordo com Ortiz (2006) não é difícil notar um movimento antagônico de forças e de distribuição de riquezas. Há no mundo atual inúmeros exemplos eloquentes de barbárie social, na qual indivíduos que habitam lugares geográficos distintos situam-se no limiar da sobrevivência. Porém, segundo este autor, há outras formas de desigualdades veladas que se constituem simbolicamente em pontos nevrálgicos do universo da cultura e interferem diretamente na conduta dos indivíduos, como o consumo - espaço referência na organização dos estilos de vida e campo da diferenciação e das desigualdades em esfera mundial.

Ao considerar o escopo deste estudo, convém enfatizar que o impulso pelo consumo desenfreado no sistema fast fashion torna as peças do vestuário obsoletas em um prazo ínfimo, uma vez que a lógica que fundamenta o processo de globalização é produzir materiais que imprimam sua efemeridade.

Deste modo, além das peças de roupas saírem de moda em um curto período de tempo para dar lugar a outras peças que se tornam novos objetos de desejo do consumidor, na sociedade do descartável as peças de roupas sazonais são mal fabricadas, rasgam sozinhas e têm vida útil extremamente reduzida.

Nesta direção, segundo Antunes (2011), a configuração que o capitalismo assume na sociedade atual acentua a lógica da destrutividade (MÉSZÁROS, 1989), a qual é a expressão mais impetuosa da crise estrutural que devasta o processo de (des)sociabilização contemporânea. Neste sentido, diz o autor: 
Destrói-se a força humana que trabalha; destroçam-se os direitos sociais; brutalizamse enormes contingentes de homens e mulheres que vivem do trabalho; torna-se predatória a relação produção/natureza, criando-se uma monumental sociedade do descartável, que joga fora tudo que serviu como embalagem para as mercadorias e o seu sistema, mantendo-se, entretanto, o circuito reprodutivo do capital (ANTUNES, 2011, p. 191).

A partir destas considerações, nota-se que, na sociedade do consumo, as pessoas incentivam e financiam direta ou indiretamente o fast fashion contribuindo, de um lado, para o enriquecimento exacerbado de uma minoria - os grandes empresários das famosas marcas da moda - e, de outro, para a manutenção do trabalho em condições sub-humanas em países que desrespeitam ou em que inexistem as leis trabalhistas.

Portanto, falar em democracia da moda quando incita-se a compra de uma quantidade maior de peças de roupas de qualidade questionável, para que sejam propositadamente descartadas com rapidez, mostra ser tão somente um artifício para ocultar a exploração do trabalho e a destruição da natureza, uma vez que este impede a conscientização e aplaca qualquer tentativa de reivindicação das camadas populares excluídas das mais altas esferas econômicas e sociais.

\section{Slow fashion: proposta de resistência ou dissimulação?}

O termo slow fashion foi criado pela inglesa Kate Fletcher, consultora e professora de design sustentável do Centre for Sustainable Fashion. Para cunhar esta expressão, Fletcher (2007) inspirou-se no movimento slow food, fundado em 1986, na Itália, pelo jornalista e sociólogo Carlo Petrini, o qual propunha tanto ao produtor, como ao consumidor responsabilidade ambiental no sentido de fortalecer a cultura comunitária, os costumes e as tradições de uma região, quer estivesse relacionada à culinária e às atividades agrícolas locais, quer estivesse ligada a outros aspectos culturais.

O slow food, ao enfatizar a produção e o consumo consciente de alimentos, também apresentava como proposta instigar um olhar criativo e atento, edificado nas recordações geracionais, com o intuito de enriquecer o repertório histórico dos indivíduos de uma comunidade e propiciar-lhes não apenas a criação de renda para as famílias locais, como a inserção em uma realidade fundada pela qualidade de vida e pela sustentabilidade (FLETCHER \& GROSE, 2011). 
Os princípios originados pelo slow food foram tão fortemente propagados que repercutiram em outras esferas de atuação, como na área da moda, dando origem ao slow fashion (CATALDI, DICKSON \& GROVER, 2010).

De acordo com Bresser (2010), o termo slow fashion configura-se como uma proposta alternativa ao fast fashion, pelo fato de surgir em contrapartida ao consumo desmedido, descartável e não sustentável e, ainda, defender a produção de peças duráveis e de qualidade.

O slow fashion, segundo Fletcher (2007), não se apresenta meramente como uma tendência ou um processo transitório, mas se propõe a representar um movimento que sugere conscientização no que diz respeito ao consumo das peças de vestuário. Neste sentido, o slow fashion consiste em um processo de desaceleração do consumo, com produção de peças perenes e de qualidade, para serem usadas de forma permanente e não provisória.

Para Lima (2013), a ideia do slow fashion é não apenas fazer uso de materiais recicláveis, mas agir de forma ética com os trabalhadores e rever a estrutura do sistema da moda, a partir de mudanças empreendidas em relação ao planejamento das coleções, da produção, da comercialização e da valorização dos produtos. Por conseguinte, o slow fashion propõe uma abordagem diferente em que designers, produtores, revendedores e consumidores estejam em constante interação.

Fletcher e Grose (2011) acrescentam que no slow fashion não recorre-se a trabalhadores temporários ou subcontratados, nem tampouco obriga-se trabalhadores a fazerem horas extras excessivas, a fim de cumprirem a entrega de encomendas imprevisíveis, com prazos impossíveis. Ao contrário, busca-se ofertar aos trabalhadores a possibilidade de garantia de empregos estáveis, com horários regulares e oportunidades de promoção.

Na esteira deste sistema, a pesquisadora holandesa de tendências, Li Edelkoort, lançou, em 2015, um Manifesto anti-fashion (FAIRS, 2015) com o objetivo de tecer críticas ao cenário atual do mundo da moda e promover uma ruptura com as práticas vigentes e os valores do fast fashion.

O Manifesto anti-fashion (FAIRS, 2015) não apenas enfatizava a diversidade e a exclusividade em oposição à produção em massa; a permanência e a durabilidade em oposição à efemeridade e ao descartável; o local/nacional em oposição ao global, como também valorizava aspectos como: o trabalho manual e colaborativo; a busca de conhecimentos sobre tecidos e criação têxtil; o prolongamento da vida útil das peças de vestuário; o planejamento da redução e/ou eliminação de resíduos sólidos; o uso de técnicas tradicionais de confecção; e a utilização de matéria-prima com princípios ecológicos e de materiais disponíveis na região local. 
Deste modo, estilistas contrários ao ritmo alucinante da moda e adeptos ao slow fashion passaram a focar suas criações em peças artesanais e exclusivas feitas à mão, em pequenas quantidades e com materiais diferenciados (WATSON \& YAN, 2013).

Segundo Fletcher (2007), se no sistema fast fashion há um crescimento elevado de pessoas, principalmente de mulheres e de crianças, trabalhando nas fábricas de roupas cerca de 16 horas por dia ou mais, sem descanso e em condições desumanas, no sistema slow fashion há a valorização dos trabalhadores envolvidos em todo o processo de produção, uma vez que a confecção das peças é realizada de forma lenta e em pequena escala.

O discurso propalado pelos adeptos ao slow fashion enfatiza que nesta nova abordagem designers, produtores, compradores, varejistas e consumidores preocupam-se com ações de sustentabilidade e com o impacto de seus produtos nos trabalhadores e na sociedade, priorizando a variedade, a criatividade e a qualidade das roupas (JOHANSSON, 2010).

Todavia, apesar de a cadeia produtiva artesanal, caracterizada pelo pluralismo de materiais (sustentáveis), de possibilidades artísticas, de estruturas de recursos e de atividades organizacionais não convencionais, contrastar e desafiar o padrão do modelo de negócios caracterizado pela obsessão da moda rápida e pelo estilo globalizado, nota-se que o slow fashion ainda mantém a preocupação com a alta lucratividade e a rentabilidade. Neste sentido, a moda pautada no slow fashion acaba apresentando um custo elevado ao consumidor.

Os criadores do slow fashion, por sua vez, justificam os altos preços enfatizando a qualidade dos materiais usados, a durabilidade das peças de roupas, a valorização dos trabalhadores e a responsabilidade no processo de produção, no sentido de provocar menos impacto ao ambiente (FLETCHER, 2007).

Em relação a este aspecto, os idealizadores do slow fashion reconhecem que, neste modelo, o consumidor compra menos produtos em maior valor, uma vez que qualidade e exclusividade podem acabar custando mais. No entanto, empreendedores e varejistas de roupas que se apropriam do sistema slow defendem a ideia de que uma distribuição mais justa do preço através das cadeias de fabricação do vestuário faz parte do negócio e o slow fashion também precisa garantir rentabilidade.

Assim, apesar de o slow fashion encorajar modelos de negócios inovadores e diversos como: a abertura de cooperativas têxteis, a compra de roupas em brechós, o uso de peças vintages, a produção de roupas com materiais reciclados, a customização de roupas, o aluguel e a troca de roupas em feiras e a criação de Roupatecas (GARCIA, 2015), nota-se na maior parte destas iniciativas a predominância da preocupação com a lucratividade e a rentabilidade. 
Convém mencionar que, as primeiras Roupatecas foram idealizadas em cidades europeias como: Amsterdã, Paris e Barcelona tendo como modelo um novo conceito de consumo consubstanciado nos princípios do desenvolvimento sustentável (ONU, 1987). As Roupatecas referem-se a guarda-roupas compartilhados onde os clientes pegam emprestado roupas, acessórios e calçados de marcas da moda (ou não), pagando um valor fixo mensal. Para se ter uma ideia, no início de 2017 os valores das assinaturas mensais praticados por algumas roupatecas do país variavam de $\mathrm{R} \$ 100,00$ a $\mathrm{R} \$ 300,00$ (PEDROSO, 2017).

Atualmente, as marcas existentes no sistema slow fashion disseminam nas redes sociais que "precisam ser rentáveis, competitivas e buscar visibilidade no mercado" (BLOG SLOW DOWN FASHION, 2016), justificando os preços altos pelo fato de incorporarem recursos sustentáveis e salários justos que acabam se refletindo no valor real de cada peça.

No Brasil, as poucas marcas e projetos alinhados aos valores do movimento slow fashion sob o slogan do consumo consciente e sustentável e do relacionamento ético e justo, comercializam peças de roupas a preços exorbitantes para os padrões econômicos da maioria da população do país.

Nesta direção, lojas de aluguéis de roupas e de artigos para customização do vestuário, brechós, bazares e roupatecas, nas grandes cidades brasileiras, transformam-se em locais de luxo e de frequentadores que se dizem criativos, repletos de estilo, conscientes $e$ ecologicamente corretos.

Portanto, apesar de o discurso a favor do slow fashion reiterar que é possível produzir moda de forma consciente e denunciar as deficiências de um sistema que explora o trabalho e destrói os recursos naturais, depreende-se, através desta pesquisa, que é preciso que os seus reais objetivos sejam questionados, afinal para que as pessoas que vivem do trabalho adotem esse novo sistema, faz-se necessário que elas tenham poder de compra e possam consumir o slow fashion, o qual atualmente apresenta-se restrito e com valor demasiadamente elevado.

Com efeito, se o slow fashion não é acessível a toda a população, então, o referido sistema é elitista e representa apenas um ícone de status e não uma mudança, de fato, no consumo da moda e no processo de conscientização acerca do trabalho escravo.

Portanto, faz-se necessário questionar o valor das peças das roupas e o público para quem o mercado do slow fashion está direcionado, uma vez que somente as classes de alto poder aquisitivo podem aderir a esta nova filosofia e participar das tendências da moda de forma consciente, conforme sinaliza o sistema slow.

Ao considerar que a classe trabalhadora vivencia não apenas acentuados níveis de redução ou precarização do trabalho, mas também o vertiginoso crescimento do desemprego 
estrutural, acompanhado de um fenômeno de discriminação, segregação e exclusão social ainda mais marcante (ANTUNES, 2011), não se pode exigir dos indivíduos pertencentes às camadas populares um discurso de adesão ao slow fashion, quando a sua preocupação primordial é a obtenção dos bens necessários à manutenção da vida (MARX \& ENGELS, 2007).

Neste momento, ao procurar problematizar o termo slow fashion, faz-se emergente trazer à tona Vigotski (2007), para quem a formulação dos conceitos envolve atos de complexidade, dinamismo e interfuncionalidade, construídos através da inserção do indivíduo na cultura e mediados pelas relações com outros homens.

De acordo com Vigotski (2009), significado e sentido constituem os processos de significação. Enquanto o significado possui em sua essência determinado grau de estabilidade que se refere à generalização e ao estabelecimento das práticas sociais humanas, sendo atribuído convencionalmente pela sociedade, o sentido exprime a relação pessoal, de natureza social, que o homem mantém com este significado. Como o sentido advém da experiência coletiva da humanidade e emerge nas/das práticas sociais efetivas (e coletivas), com o tempo, pode modificar o significado instituído nas situações concretas. Trata-se de uma relação dialética em que o significado pode alterar o sentido, ao mesmo tempo em que o sentido pode alterar o significado.

Na conjuntura da globalização e das reformas neoliberais, por mais que o significado do conceito de slow fashion seja fixado ideológica e culturalmente, como o sentido sempre decorre das práticas reais e concretas (VIGOTSKI, 2009), ou seja, como os indivíduos, ao se apropriarem de determinado conceito experienciam vivências distintas nas tramas das relações sociais cotidianas em que está envolvido em sua cultura, vivências estas na maioria das vezes diferentes daquelas prescritas pelo significado de tal conceito, então pode haver a cisão, ainda que seja por uma linha tênue, entre o sentido e o significado imposto pela ordem social vigente.

A partir das considerações teóricas de Vigotski (2009), nota-se que o conceito de slow fashion, na sociedade Imperialista, avulta-se como o poderoso canto da sereia que enfeitiça, obscurece a visão e arrasta o ser humano, sem que ele perceba, para as profundezas do oceano.

Nesse ínterim, Ortiz (2011) pontua análises cruciais ao argumentar que o Estado, enquanto totalidade que organiza impetuosamente a realidade concreta, circunscreve os contornos da identidade de uma Nação, de tal modo a dissolver de todas as formas possíveis a heterogeneidade das culturas populares com vistas à homogeneização do discurso ideológico.

Cabe, então, questionar não apenas sobre quais valores, interesses e forças estão orientando as construções simbólicas delineadas pelo Estado e pelo Mercado em torno do termo 
slow fashion e o combate ao trabalho escravo na sociedade atual, mas também quais grupos específicos, propósitos e projetos estão em curso em sua elaboração (ORTIZ, 2011).

Cumpre lembrar que Ortiz (2006) assenta o termo culturas populares como manifestações que não se restringem a um sistema único, com traços comuns, mas ao contrário, pelo fato de corresponder à diversidade de grupos sociais - os quais, por sua vez, ritualizam vivências distintas -, deve ser compreendida como heterogênea, fragmentada e plural.

Deste modo, como forma de problematizar as vicissitudes que cercam os debates sobre a expressão ontológica da cultura de uma Nação, Ortiz (2009) sublinha a pluralidade de discursos forjados por grupos sociais distintos, em momentos históricos diversos, a partir de uma multiplicidade de manifestações culturais. Decorre desta assertiva o fato de que toda tentativa de fixidez à uma pretensa noção de cultura encerra um domínio político.

Assim, de acordo com Ortiz (2009), vislumbrar outro caminho implica em travar um embate contra as ideologias hegemônicas e, concomitantemente, admitir a historicidade de um processo social no âmago do qual proposições alternativas possam ser contrapostas.

Portanto, seguindo as premissas teóricas de Vigotski (2007, 2009) e de Ortiz (2009, 2011), a formação/apropriação/problematização, de modo crítico, da significação dos conceitos na cultura, pode potencializar e modificar qualitativamente a consciência do homem na luta contra a alienação, tornando-o mais crítico e humanizado.

\section{Conclusões}

Ao longo da trajetória deste trabalho procurou-se, primeiramente, clarificar as demarcações conceituais do termo fast fashion, forjado pela indústria da moda, enfatizando as relações entre este sistema de produção e o trabalho escravo na sociedade contemporânea. Posteriormente, buscou-se circunscrever a significação do termo slow fashion, com o intuito de desvendar os pressupostos ideológicos contidos nesse novo movimento de consumir moda.

Uma vez delimitado o escopo deste trabalho, ao ancorar-se nas preleções de Vigotski (2007, 2009) e de Ortiz $(2009,2011)$, foi possível depreender que é a partir da vivência no mundo objetivo e da apropriação das formas culturalmente determinadas de organização do real e dos signos produzidos pela cultura que os indivíduos experienciam e constroem processos de significação, os quais constituem uma espécie de código para interpretar o mundo e para desvelar a essência da realidade aparente.

Com efeito, um campo ideológico, pelo fato de estar inextricavelmente ligado ao uso da linguagem e à cultura, possui o seu próprio modo de orientar e refratar a realidade. Portanto, 
cada domínio ideológico dispõe de uma função específica na vida social em razão de seu caráter semiótico (ORTIZ, 2009).

A partir destas considerações tornam-se evidentes as mudanças que ocorrem no conceito de slow fashion presente nos interstícios da linguagem da moda e a maneira como uma sociedade apropria-se do discurso ideológico e por este mesmo discurso é apropriada.

Em face à exposição realizada, nota-se que os pressupostos ideológicos contidos no conceito de slow fashion revelam que este termo é determinado pelas diretrizes economicistas, de natureza mercadológica, ostentadas pelo economia neoliberal e pela cultura global (ORTIZ, 2011).

Se por um lado o fast fashion apresenta-se inextricavelmente relacionado ao trabalho escravo na sociedade contemporânea, o slow fashion evidencia que enquanto o capital for o fundamento das relações de produção, qualquer manifesto anti-fashion produzirá mudanças ínfimas, uma vez que a prioridade do capitalismo é o lucro e não a correção de distorções de seu próprio sistema.

Deste modo, as proposições teóricas deste trabalho resvalam na seguinte assertiva: não basta refletir sobre a descartabilidade da moda e aderir ao slow fashion como principal linha de ação para combater o trabalho escravo nas cadeias produtivas da indústria da moda. A questão que prioritariamente se coloca é problematizar e enfrentar veementemente as imposições de um sistema econômico que se reestrutura de modo contínuo, no intuito de reinar soberano, reengendrando novas formas de organização de trabalho extremamente injustas, desiguais e desumanas.

\section{Referências}

ANTUNES, R. Adeus ao trabalho: ensaio sobre as metamorfoses e a centralidade no mundo do trabalho. São Paulo: Cortez, 2011. 213 p.

BARROS, C. J. Trabalho escravo nas oficinas de costura (Fascículo). São Paulo, 2016. Disponível em: http://reporterbrasil.org.br/wp-content/uploads/2016/06/Fasc\%C3\%ADculoConfecção-Textil_Final_Web_21.01.16.pdf. Acesso em: 30 jan. 2017.

BLOG SLOW DOWN FASHION. Conheça os 10 valores do Slow Fashion. 27 abr. 2016. Disponível em: https://www.slowdownfashion.com.br/single-post/2016/03/14/Ola. Acesso em: 02 jun. 2017.

BRESSER, D. Você sabe o que é fast fashion? Moda Ig, 2010. Disponível em: http://moda.ig.com.br/modanomundo/voce-sabe-o-que-e-fast-fashion/n123779569297/.

Acesso em: 17 fev. 2017. 
CAETANO, C. C. O cross-branding e a cocriação no âmbito do varejo de moda. 2013. 172 p. Dissertação (Mestrado em Têxtil e Moda) - Escola de Artes, Ciências e Humanidades, Universidade de São Paulo, São Paulo, 2013.

CATALDI, C.; DICKSON, M.; GROVER, C. Slow Fashion: tailoring a strategic approach towards sustainability. 2010. 102 p. Dissertação (Master of Strategic Leadership towards Sustainability) - School of Engineering, Blekinge Institute of Technology, Karlskrona, Sweden, 2010.

CIETTA, E. A revolução do fast fashion. São Paulo: Estação das Letras e Cores, 2010. 263 p.

FAIRS, M. Li Edelkoort publishes manifesto explaining why "fashion is obsolete". Dezeen Magazine, 02 Mar. 2015. Disponível em: https://www.dezeen.com/2015/03/02/li-edelkoortmanifesto-anti-fashion-obsolete/. Acesso em: 05 Mai. 2017.

FLETCHER, K. Slow Fashion. Ecologist, sept. 2007. Disponível em: http://theecologist.org/green_living/clothing/269245/slow_fashion. Acesso em: 15 ago. 2016.

; GROSE, L. Moda \& Sustentabilidade: design para mudança. São Paulo: SENAC São Paulo, 2011. 192 p.

GARCIA, G. Guarda-roupa compartilhado: conheça uma roupateca em São Paulo. Inteligência de Moda, 04 nov. 2015. Disponível em: http://www.crisguerra.com.br/2015/11/04/guarda-roupa-compartilhado-por-assinaturamensal-conheca-a-roupatecal. Acesso em: 15 jun. 2017.

IANNI, O. Globalização: novo paradigma das ciências sociais. Estudos Avançados, São Paulo, n. 8, v. 21, p. 147-163, 1994.

A sociedade Global. Rio de Janeiro: Civilização Brasileira, 2008. 194 p.

JOHANSSON, E. Slow fashion - the answer for a sustainable industry? 2010. 94 p. Dissertação (Master in Applied Textile Management The Swedish School of Textiles - The Swedish School of Textiles, University of Boras, Sweden, 2010.

KAPLAN, A. M.; HAENLEIN, M. Users of the world, unite! The challenges and opportunities of social media. Business Horizons, Paris, n. 53, p. 59-68, 2010.

LIMA, V. F. T. O Prolongamento da vida útil do vestuário de moda como alternativa para a redução de seu impacto socioambiental. 2013. 106 p. Dissertação (Mestrado em Têxtil e Moda) - Escola de Artes, Ciências e Humanidades, Universidade de São Paulo, São Paulo, 2013.

MARX, K; ENGELS, F. A ideologia alemã. São Paulo: Boitempo, 2007. 643 p.

.Manifesto comunista. São Paulo: Boitempo: 2010. 271 p.

MARZOCHI, S. F. Mundialização, modernidade, pós-modernidade: entrevista com Renato Ortiz. Ciências Sociais Unisinos, v. 43, n. 1, p. 103-105, jan./abr. 2007.

MELLO, H.; BATISTA, A.; GUSMÃO, J. Entrevista com Renato Ortiz: "Porque o mundo é 
comum, o diverso torna-se importante”. Cadernos Cenpec, São Paulo, v. 5, n. 1, p. 183-196, jan./jul. 2015.

MÉSZÁROS, I. Produção destrutiva e Estado capitalista. São Paulo: Ensaio, 1989. 105 p.

ORGANIZAÇÃO DAS NAÇÕES UNIDAS. Relatório Brundtland, Nosso Futuro Comum, 11 de dezembro de 1987. Disponível em: http://www.un.org/documents/ga/res/42/ares42187.htm. Acesso em: 20 fev. 2017.

ORGANIZAÇÃO INTERNACIONAL DO TRABALHO. Convenção n. 29 aprovada na $14^{a}$ Reunião de Genebra de 1930 (Decreto no 41.721, de 25 de junho de 1957, Brasília. Disponível em: http://www.ilo.org/brasilia/convencoes/WCMS_235021/lang--pt/index.htm. Acesso em: 26 jul. 2016.

ORGANIZAÇÃO INTERNACIONAL DO TRABALHO. Relatório sobre as Estimativas Globais Econômicas do Trabalho Forçado da Organização Internacional do Trabalho, 20 de maio de 2014, Brasília. Disponível em: http://www.ilo.org/brasilia/temas/trabalhoescravo/lang--pt/index.htm. Acesso em: 26 jul. 2016.

ORTIZ, R. Mundialização: saberes e crenças. São Paulo: Brasiliense, 2006. 211 p.

Globalização: notas sobre um debate. Sociedade e Estado, Brasília, v. 24, n. 1, p. 231254, jan./abr. 2009.

. Mundialização e Cultura. São Paulo: Brasiliense, 2011. 236 p.

PEDROSO, P. Guarda-roupa compartilhado oferece acesso a peças por assinatura em SP. Revista da Folha de São Paulo, 08 de janeiro de 2017. Disponível em: http://www1.folha.uol.com.br/saopaulo/2017/01/1847632-guarda-roupa-compartilhadooferece-acesso-a-pecas-por-assinatura-em-sp.shtml. Acesso em: 30 mai. 2017.

SANTOS, M. Por uma outra globalização: do pensamento único à consciência universal. Rio de Janeiro: Record, 2003. 174 p.

VIGOTSKI, L. S. A formação social da mente. São Paulo: Martins Fontes, 2007. 191 p.

A construção do pensamento e da linguagem. São Paulo: Martins Fontes, 2009. 496 p.

WATSON, M.; YAN, R. N. An exploratory study of the decision processes of fast versus slow fashion consumers. Jornal of Fashion Marketing and Management, EUA, v. 17, n. 2, p. 141159, sept. 2013. 